\title{
The novelty of the concept of paraphrenia
}

\author{
Simona Trifu, University of Medicine and Pharmacy "Carol Davila" Bucharest \\ Alexandra Popescu, Clinical Hospital for Psychiatry "Alex. Obregia" \\ Amelia Damiana Trifu, "Tudor Vianu" National College of Computer Science
}

\section{HOSPITAL ADMISSION MOTIVES:}

The patient, who has a vast psychiatric history, is brought to the emergency room by the Police, presenting: - Psycho-motor agitation - Verbal and physical aggressiveness - Verbal and ideological incoherence • Disorganized behavior

The symptomatology is induced by failure to follow the treatment. He is admitted non-voluntarily in a state of urgency.

\section{DISEASE HISTORY:}

$\square 35$ years old patient, multiple admissions, known as having a Paranoid Schizophrenia diagnostic since 2014.

$\square$ At the age of 25 - he was convicted for 7 years, cumulated for many criminal deeds, such as violence towards the Police and robbery with assault.

$\square$ The psychotic phenomena first appeared during his imprisonment in the shape of auditory hallucinations.

The delusional is dominated by aggression and violence (swords, seams, cut throats and hearts, concrete slabs that crush, torpedoes, dragons, hyenas, demons) !!!

Cotard Syndrome?

Arguments in favor of

- imortality („my heart was cut yet it reconstructed itself”, „my throat was cut and regenerated", "Someone poured concrete on me and nothing happened ")

- grandeur („666 million km long penis”, „80 hearts”, „sould divised in 1000 pieces")

- Death concerns („satan was dead before he was in the tomb”). Arguments against

The feelings that accompany the delusional macromanic idea are from the spectrum of grandeur and omnipotence and are not of a depression-micromanic nature.

\section{SYNDROMES:}

Psychomotor agitation syndrome: - Abnormal behavior Modified motor expression - Instincts that are out of voluntary control - Destruction of consciousness

Paranoid syndrome: - Unsystematized delirium with persecutory and suspicious content - Hallucinations, especially imperative auditory ones

Mental automatism Syndrome Clérambault: - Delirium of influence (xenopathy) patient is convinced that his thoughts are no longer his - Pseudo-hallucinations

DIAGNOSTIC:

AXIS I: Paranoid Schizophrenia

AXIS II: Antisocial personality spectrum traits

AXIS IV: Alcohol abuse, criminal conflicts, lack of social network

\section{DIFFERENTIAL DIAGNOSTIC :}

\section{Differential diagnostic with axis I (Paranoid Schizophrenia):}

Schizo-affective disorder - expansive episode: an argument for, is the expansive nature of the speech through its grandeur and omnipotence, which affects the process of thinking rather than the emotionality (mood), which advocates for the diagnosis of schizophrenia. Also, during the counter - transference, the pacient does not contaminate his presumtive expansiveness.

Paraphrenia: It is characterized by a chronic, hallucinatory systemic delusion, of magical character, whose imaginative abilities go as far as the creation of an imagined world ("I went to sleep in one room and woke up in another place").

What supports the diagnosis of schizophrenia is that the delirium is incoherent, associated with the destruction of personality, while the paraphrenic patient often retains a mechanism of adaptation to reality.

Organic personality disorder: Denying the violent acts ("I did not slap, nor did I curse at my neighbour", "I did not fight people, I fought demons") brought into discussion the epileptoid raptus, the markers of organic cerebral measured on EEG deny this hypothesis.

The patient often remembers an event in which a concert block fell on his head which raised the suspicion of a possible barin trauma, for which a CT-scan was requested - it denied intracerebral posttraumatic lesions.

Histrionic personality disorder: Fascination, seductiveness, impulsivity and manipulation are classic histological features that we can highlight in our patient, which could mislead. However, specialized literature mentions that antisocials, when in contact with psychiatric medical staff, put on a histronic mask in order to receive specialc care and attention.

CASE PARTICULARITIES:

Schizophrenia, which had an onset that overlapped an antisocial personality who had a criminal record of theft and violence, resistant to standard antipsychotic treatment, for which Clozapine treatment is brought into discussion in order to avoid forensic risks.

DISCUTIONS:

It is necessary to assess the degree of danger, the necessity of prolonged admission in the absence of family support and social support network and non-compliance with treatment.

Permanent treatment with Clozapine alongside a slow release antipsychotic, the advantages and disadvantages of electroconvulsive therapy have been discussed.

Electroconvulsive therapy can be considered as a promising alternative for refractory symptoms, its effectiveness is synergistic with that of antipsychotics. 